be tolerably even. It is advisable to have the ground next the curb well trodden on and rammed before the pavement is laid, otherwise there will be an unseemly hollow next the curb. In laying, the rough stuff is put down first and rolled tolerably firm, then the second quality is put on, then the third, and when the whole has been raked level, a little of the finest material is sifted on through a sieve with $\frac{1}{8}-$ in. meshes, and a litlle fine white shingle or Derbyshire spar is sprinkled on the top. The whole must now be well rolled. The best roller is a water ballast roller, which at first is used without ballast, and well wetted to prevent adhesion of the material, and, when the pavement is slightly consolidated, the full weight should be applied.

For heavy cart traffic the material should be made of shingle only, heated and mixed as above, and well rolled. Both descriptions of parement are laid best and most easily in warm weather, and should be rolled when the sun has warmed it well. Those parts in angles should be well rammed and trimmed off with a light shovel.

Though apparently a simple manufacture, there is a little difficulty in ascertaining the proportion of tar to gravel or cinder-dirt. A little experience will only be necessary in this, as well as in all other manufactures, to enable anyone to carry it out successfully.

This pavement cannot be spoken of too highly, as it is cheap, wears well, and can be easily repaired. The colour, which never can be made to equal York flag, and the smell for some time after it is laid, are the only objections to its use ; it can be laid with a good profit in any district at $\mathrm{I} s .4 d$. per square yard; and besides being a boon to the public, who must otherwise walk on gravel, is a great advantage to gas companies. To them it provides a remunerative outlet for their tar, which often otherwise must be sold at a low price to distant distillers.

A late paragraph, which appeared in the daily press, states that it is proposed to pave the streets of London with stone laid in asphalte instead of lime grout. This is just a more systematic application of the above-described plan; for the tar, by being boiled and thrown on hot stones, becomes an elastic asphalte.

\section{INDIAN BARRACKS}

$\mathrm{R}^{\mathrm{E}}$ CENT discussions regarding the new Indian Barracks have shown the necessity for an adequate knowledge of physical science on the part of all engineers who have to cope with great natural forces.

These costly structures have been described as "sun traps," meaning thereby that the materials and details have been so selected, that instead of the interior of the rooms being as cool as, if not cooler, than the outside, it is cooler for the men to be in the open air under the sun. It is true that this objection has been raised at very few stations, but with adequate knowledge on the part of the architects, it ought never to have been raised at all. The barracks complained of are stated to be brick structures of the usual dark colour, with verandahs supported not on light easily heated and easily cooled columns, but on massive piers and arches like a bridge. The roofs have been constructed almost as they would have been at home, and no adequate means have been adopted for protecting the walls from sun-radiation. Of course the great mass of brickwork becomes heated during the day, and heats the air outside and inside the rooms at night, while the structure of the roof is such that the interior is heated both by direct conduction and radiation. Now surely such mistakes might have been avoided. There are such things as nonconducting materials to be had, and double walls with a ventilating air space between are not an uncommon expedient in this country for keeping out both heat and cold. Again, there is such a thing as white plaster or whitewash for outside walls, which reflects a large portion of the solar heat. Double roofs are not unknown, we believe, in India, and it is possible to construct such a roof as to interpose not only an air current between the outer and inner layer of the roof, but to prevent the radiation of the inner surface of the outer layer passing through the inner layer. These are very elementary applications of physical laws to Indian house construction, and how little they have been attended to may be inferred from a fact which has been stated-viz., that these barracks have been roofed with slate. The ordinary laws of conduction and radiation of heat appear to be at a discount in the Indian works department.

\section{THE PROVINCE OF MINERAL CHEMISTRY}

PROFESSOR KOLBE has recently succeeded to the directorship of the fournal fiur Praktische Chemie, rendered vacant by the decease of Erdmann, its original founder; and in his hands this periodical will doubtless become the recognised organ of the modern Leipsic School of Chemistry. Dr. Kolbe, in the first number 0 the new series of this work, has signalised his succession to the office of editor by an introductory essay, seiting forth his opinions upon what he considers must be the future aim of the student of Inorganic Chemistry. Organic Chemistry, once the neglected sister of Inorganic Chemistry (to use the Professor's phraseology), has become so courted and honoured since Liebig introduced her as a young science into the chemical world, that little by little her relative has sunk into comparative obscurity. But the time has now arrived when, in Kolbe's opinion, it is evident that Inorganic Chemistry has not merited this neglect, but that she has it in her power to bestow rewards not less precious than those of Organic Chemistry, upon those who devote themselves to her service.

Much of the attractiveness of Organic Chemistry must, according to Kolbe, be traced to the zeal with which the origin of the almost numberless cases of Isomerism in organic compounds is being searched out; indeed, this zeal has nearly displaced the lively interest in Inorganic Chemistry created by the discovery of Isomorphism. This cause can never actuate the investigator in the domain of Inorganic Chemistry-at least not to the same extent-and for the reason adduced by Kolbe, that Isomerism cannot possibly occur in inorganic compounds to anything like the same degree as among organic substances, owing to the greater simplicity of constitution possessed by the former class. That so few cases of Isomerism have been discovered in Inorganic Chemistry is undoubtedly due to the fact that hitherto we have neglected to investigate mineral substances with special regard to their chemical constitution.

In order to prove the truth of this latter assertion Kolbe asks how can we frame anything like a reply to any question respecting the chemical constitution of the naturallyoccurring silicates-felspar, for example? What are the proximate constituents of this compound, and what are their respective functions?

In half a dozen brief sentences Kolbe disposes of all our knowledge upon this subject, beginning with the views of Berzelius, by whom felspar-the typical silicate-was regarded as possessing a constitution analogous to that of dehydrated alum-that is, as a double salt of neutral silicate of alumina and silicate of potash; and ending with Gerhardt, who thought to explain the constitution of this and all bodies by his theory of types, or, in the expressive language of Professor Kolbe- "mit de1 mechanischen Handhabung eines todten Schematismus."

The greater portion of the paper is devoted to Kolbe's theoretical views upon the nature of felspar, and he suggests a number of structural formulæ to explain its constitution according to our present opinions upon the quantivalence of the component elements. Whether, however, any of these formulæ represent the actual con- 
stitution of felspar, or if, indeed, its true nature can be represented by such formulæ, is a question which Kolbe leaves untouched, for the simple reason that the necessary experimental foundation from which alone valid arguments can be drawn, is entirely wanting.

Professor Kolbe concludes this remarkable paper by defining what should be the future aim of the student in Mineralogical Chemistry. He must not now rest content with a mere quantitative analysis, or with the empirical deduction of rational formulæ from the results of such analysis. Such a process can never fully elucidate the chemical constitution of inorganic compounds. This can only be accomplished by a careful and systematic study of the decomposition, syntheses, and substitutions; in other words, by the application of methods of research similar to those which have yielded such splendid results in Organic Chemistry,

T. E. THORPE

\section{NEW OBSERVATORY IN THE SOUTHERN HEMISPHERE}

$\mathrm{THE}$ following statement with regard to the Cordova 1 Observatory, to the foundation of which we have before referred, is extracted from the last number of Silliman's American Fournal of Science and Arts.

"The Argentine Congress voted to establish a national observatory at Cordova, at the instance of President Sarmiento, and through the exertions of the present Minister of Public Instruction, Dr. Avelleneda, who invited me to organise and take charge of it, knowing my desire to extend the catalogue of the southern heavens beyond the limit of $30^{\circ}$ to which the zones of Argelander extend. Bessel went through the region from $45^{\circ} \mathrm{N}$. to $15^{\circ} \mathrm{S}$. with systematic zone observations at Königsberg, which have since been reduced and published in two catalogues by Weisse of Cracow. Argelander carried the same systematic scrutiny with the Meridian Circle, from Bessel's Northern limit to the pole, and afterwards from Bessel's Southern limit to $30^{\circ} \mathrm{S}$.

"Since then Gilliss has observed a series of zones for $30^{\circ}$ around the south pole; but the reduction of these, although very far advanced, was not completed at the time of his death, and the MS. is now stored somewhere in Washington. Let us hope that it may at some time be recovered, the work completed and given to the world.

"My hope and aim is to begin a few degrees north of Argelander's southern limit, say at $26^{\circ}$ or $27^{\circ}$, and to carry southward a system of zone observations to some declination beyond Gilliss's northern limit, thus rendering comparisons easy with both these other labours, and permitting the easy determination of the corrections needful for reducing positions of any one of the three series to corresponding ones for the other. It is of course impossible to arrange in advance the details of such an undertaking, but my expectation is to go over the region in question in zones $2^{\circ}$ wide (except in the vicinity of the Milky Way where the width would be but one-half as great), up to a declination of about $55^{\circ}$, after which the width would be gradually increased as the declinations became greater. Within these zones all stars seen as bright as the gth magnitude would be observed, so far as possible, moving the telescope in altitude when no bright star is in the field until some one becomes visible, according to the well known method of zone-observations.

"For reducing the observations, differential methods will probably be employed, inasmuch as the time now assigned for my absence from home would be inadequate for proper discussion of the correction required for nice determinations of an absolute character. Still, it is my present purpose, so far as possible, to make such subsidiary determinations as might hereafter be needed in any attempt at computing the observations absolutely. But as I hardly venture to anticipate any opportunity of making a thorough determination of the constants of refraction, or of the errors of graduation, it seems best to arrange for a differential computation at least at first.

"It is improbable that a sufficient number of well-determined stars will be found available even for this differential reduction, and the necessity may thus be entailed of determining the comparison-stars myself, this determination, however, itself depending upon standard star places. So far as possible I propose employing those heretofore determined by me, and published by the Coast Survey, which form the basis of the star places of the American Nautical Almanac.

"With these observations of position it is my hope to combine others of a physical character to some extent; but in the presence of a plan implying so much labour and effort, it would be unwise to rely upon the possibility of accomplishing much more than the zone-work.

"The meteorological relations of the place are very peculiar, but I dare not undertake any connected series of observations bearing upon these, without self-registering apparatus, which is beyond my means.

"Cordova is one of the oldest cities, and contains the oldest university, of the Western hemisphere. It is situated in $31_{2}^{10} \mathrm{~S}$. latitude, on the boundary of the Pampa, where the land begins to rise toward the group of mountains known as the Sierra de Cordova. It is connected with Rosario, on the Parana, by the Central Argentine Railway, which has probably been already opened to travel through its entire length of about 250 miles, although information to that effect has not yet reached this country.

"The two largest instruments will be a Repsold meridiancircle of 54 inches focal length and $4 \frac{1}{2}$ inches aperture, and an equatorial by Alvan Clark and Sons, provided with the II-incin object-glass, by Fitz, lately in the possession of W. Rutherfurd, who has supplied its place by one of 13 inches. A photometer by Ausfeld of Gotha, according to Zölner's latest form, has been constructed under the supervision of Prof. Zöllner himself; a spectroscope will be furnished by Merz of Munich, and a clock by Tiede of Berlin.

"The Scientific institutions of the U.S. have afforded the expedition every possible assistance. The Coast Survey lends a circuit-breaking clock, a chronograph, and a portable transit; the Smithsonian Institution lends a zenith telescope; the American Academy of Arts and Sciences of Boston (probably) a photometer and spectroscope; the Washington Observatory and the Nautical Almanac have greatly aided the undertaking by gifts of books and by a manuscript copy of Gilliss's catalogue of Standard Stars ; and from the astronomers of England, Germany, and Russia important assistance has been freely and effectively contributed, in the order and supervision of instruments and apparatus, and by the gift of books, as well as by important and valuable suggestions.

"Four assistants will accompany me, Messrs. Miles Rock, John M. Thome, Clarence L. Hathaway, and Williain M. Davis, jun. We hope to reach Buenos Ayres not later than the middle of August.

"The building is now under construction in Boston. The means available proved inadequate for its construction according to the original plan, which was in the form of a cross, with four square rooms about its centre, and turrets at its four extremities. One half of it will be first erected, and it is hoped that the remaining portion will speedily be added."

B. A. GOULD

\section{SCIENTIFIC SERIALS}

THE greater part of the Revue des Cours Scientifunues for July 23 , is occupied by the commencement of a very able paper read before the Anthropological Society of Paris by Prof. Broca, on the Transformation of Species. Commencing with the preDarwinian theories of transformation of Blainville and Lamarck, he then proceeds to give a résumé of the theory of Darwin, and 